\title{
STERILIZATION AND UNION INSTABILITY IN BRAZIL
}

\author{
TIZIANA LEONE AND ANDREW HINDE \\ Department of Social Statistics, University of Southampton, UK
}

\begin{abstract}
Summary. Brazilian women rely on sterilization as the main source of birth control. Sterilization has been one of the causes of the steep decline in fertility in Brazil, at least since the second half of 1970. It is hypothesized that understanding couples' relationships might be key to explaining this high rate of female sterilizations. Possible reasons for the higher level of fertility among women in unstable unions than among women in stable ones could be the less effective use of contraceptive methods, or that women in unstable unions tend to use less effective or reversible contraceptive methods. In this paper discrete time modelling of the timing of sterilization according to union histories is presented. The analysis uses the calendar data of the 1996 Brazilian DHS. It is shown that women in second or higher order unions have a lower risk of sterilization. This result should be taken into account in the analysis of the determinants of female sterilization in Brazil.
\end{abstract}

\section{Introduction}

Brazil has shown a dramatic fertility decline in the last century with the total fertility rate (TFR) decreasing from 6.5 in 1930 to $2 \cdot 0$ in 2001. This decline has been considered particularly striking by most Brazilian demographers in the light of the absence of a government-sponsored family planning programme (Carvalho \& Wong, 1996; Martine, 1996; Goldani, 2001). The main reasons for the decline reside in the increased prevalence of contraceptive methods and the high number of abortions, in particular during the 1960s and 1970s.

The importance of female sterilization in Brazil has increased substantially since 1980. In 1996, 40\% of married Brazilian women aged 15-49 years were sterilized as opposed to $29 \%$ in 1986 . Female sterilization is high in Brazil, but the country is not alone in the high use of tubal ligations. In the Dominican Republic in $1991,38 \%$ of married women in the reproductive age span were sterilized. In El Salvador in 1993, this figure was $31 \%$ (UN, 1994). In the United States, the proportion sterilized among married women aged 15-44 was $24 \%$ in 1995 (CDC \& NCHS, 1998). 
The popularity of sterilization is justified by the lack of alternative methods and by the easy access to it, in particular for low-income women. It is a method that is completely controlled by the woman and it avoids inconveniences such as side-effects or ineffective use. The increase of education and the progressive rise of the number of women in the labour market have encouraged women to make more efforts to control their fertility. Furthermore, the role of mass media has undeniably been important: soap operas have brought new social behaviours and economic aspirations.

It has been demonstrated that the level of fertility in Brazil is particularly low among women who experience one union only (Leone, 2002). The reasons could be several: usually couples tend to bear a child in each union, and at the same time union instability leads to several unions of shorter duration. The fact that there is a negative relationship between the frequency of coitus and the duration of the union leads to the fact that women who experience several unions of shorter durations could be less exposed to the risk of conception in terms of time but could have an overall risk due to the greater frequency of coitus. Furthermore, as happens in Brazil, women in unstable unions tend to conceive to keep their relationship. Finally, women who have a history of unstable unions could use contraceptive methods less effectively. It could be, though, that these women are more likely to use less reliable methods rather than to use methods less effectively. This last factor has not been explored so far in the analysis of fertility trends in Brazil.

Union dynamics are one of Brazil's peculiarities. They are characterized by a high prevalence of consensual unions: $13 \%$ of women aged 15-49 years old are in a consensual union (BEMFAM, 1997). Consensual unions in Brazil have unique features deriving from the tradition of slavery: most couples in a consensual union would define themselves as husband and wife. It is therefore difficult to measure the true number of consensual unions. There has been an increase in the proportion of consensual unions in the last few decades. Since these unions are usually considered less stable than more formal unions, this has led to an overall increase in union instability characterized by an increased proportion of unions of shorter duration (Greene, 1991).

This paper analyses the relationship between time to sterilization and union dynamics in order to better understand the role of union dynamics in women's reproductive choices in Brazil. Furthermore, sterilization has been chosen as it is the most common contraceptive method and the reason for its popularity is still not completely clear. The analysis represents a first step towards a broader understanding of contraceptive dynamics and union histories.

\section{Effect of union dynamics on contraceptive choice}

\section{Type of method}

The effect of union instability on contraceptive use could be confounding: women in a stable relationship are more likely to use an effective family planning method and this could result in a lower level of fertility. 
Women in stable unions are those who are constantly at risk of conception and there is no loss of exposure. However, women in stable unions or women who believe themselves less likely to have several partners could be more likely to use more effective contraceptive methods and to use them more effectively. A woman in a stable union is more likely to use intrauterine devices (IUDs) or sterilization after having reached the desired family size. Women in stable unions can rely on the fact that it is easier for them to plan their family size with their partner. On the other hand women in unstable unions are less motivated to use a contraceptive method that involves a high commitment like sterilization, or a method like the IUD that is not easily available and that needs to be inserted by specialized hospital-based personnel. Women in unstable unions are more likely to use less effective methods such as condoms or, among the highly effective ones, the pill.

The literature on the topic is rather thin and one of the main studies by Bumpass \& Rindfuss (1982) contradicts this point of view. Using monthly contraceptive histories collected by the National Surveys of Family Growth in the US, they show that women who have experienced unstable unions are less likely to use coitaldependent methods (condoms, diaphragm) when they are about to split up. The reason for this might be the fact that when there is a crisis the couple tend to have more problems in communication, and therefore they might be less willing to use contraceptive methods that involve collaboration. This is even more evident when looking at the fact that these types of methods are less likely towards the end of the union as well. However, marital dissolution does not have a big impact on contraceptive usage and despite this effect, contraceptive use patterns following separations are very similar to those of women who remain in the same union (Bumpass \& Rindfuss, 1982).

Godecker et al. (2001) analysed the effect of union histories on the timing of sterilization in the USA using a Cox proportional hazards model. One of their main results was that cohabiting partners, generally known for having less stable unions, do not show different patterns of sterilization timing from formally married ones.

The mechanisms behind the relationship between contraceptive use and union duration are influenced by the culture and contraceptive tradition of the country, so it is not possible to generalize from the results above. It is the authors' belief that Brazilian women who are in less stable relationships and who might want to get pregnant to keep the relationship, might be more likely to rely on reversible methods rather than sterilization.

\section{Effectiveness}

The tendency of women to start their conjugal life in less formal unions creates a pattern in which many women find themselves, during their peak reproductive years, in unions which are, on the one hand, less conductive to effective fertility control and, on the other hand, less stable. (United Nations, 1988)

If considering the effectiveness of use rather that the type of method, the UN's statement about a less effective use of contraceptive methods for women in unstable unions is questionable. First of all there is no clear evidence that effective use of a contraceptive method is linked to the number of unions a woman has had. Secondly, 
the effectiveness of the use is influenced by the availability, price and knowledge of the method, and by the woman's characteristics such as education and social background, and not by the stability of the union. The stability of the union is influenced by the characteristics of the partners. If there is a difference in terms of higher risk of conception this difference might be in the use of less effective contraceptive methods rather than in a less effective use. Therefore much more emphasis should be given to the type of method that is used by union duration and by union history.

\section{Background}

What makes the situation in Brazil different from other countries where sterilization is popular, is that sterilization was not regulated by law until 1997, and the government, which funds about $70 \%$ of the surgical procedures performed in the country (Carvalho, 1997), did not provide reimbursement for tubal ligations. Nevertheless, sterilization was in great demand. For low-income women with little contraceptive knowledge and limited access to alternative options, sterilization meant efficacy and low costs in terms of information and medical follow-up. In addition sterilization became progressively more accessible for lower income women as private family planning clinics offered sterilizations free of charge to lower income women and politicians paid for sterilizations in exchange for votes (Meloni Vieira \& Ford, 1996). Doctors profited extensively from the increase in sterilizations as they were paid by the private family planning clinics to perform the sterilizations. Clinics were usually funded by international or governmental donors (Meloni Vieira \& Ford, 1996). This situation gave rise to a mutually beneficial relationship among politicians, doctors and women, associating sterilization with economic profit and political gains. As birth control rapidly diffused spatially and cut across socioeconomic strata, the number of tubal ligations escalated, stimulating unnecessary Caesarean births to circumvent hospitalization costs (women were sterilized for free after a Caesarean birth), encouraging pregnancy as a means of being sterilized, and increasing child and maternal health risks.

In order to overcome the illegality, prior to 1997 Caesarean sections were widely used. After two Caesareans sections a woman was allowed to undergo surgical sterilization. This is almost certainly the reason why the proportion of births delivered by Caesarean sections increased from 15 to 37\% between 1971 and 1996 (Merrick, 1983; Potter, 1999). The frequency of Caesarean sections was even higher in private clinics, reaching $71.5 \%$. This phenomenon has led to Brazil having the highest percentage of Caesarean sections in the world (Hopkins \& Potter, 1997). The 1996 DHS shows that $60 \%$ of all sterilizations had been performed after a Caesarean section (BEMFAM, 1997).

Caesarean deliveries have become so common that they are not used solely to justify surgical sterilization. Desire to get sterilized made them common; being common made them normal and a sign of progress. It is an increasing phenomenon for educated women to consider Caesarean section as a sign of 'civilization' (Perpetuo \& Aguirre, 1997). It is therefore difficult to highlight how much of the increase in Caesarean sections was due to the desire to get a 
sterilization, and how much of the increase of sterilization was due to the abuse of Caesarean deliveries.

In 1997 a law was finally passed allowing men and women the right to free reproductive choice (Potter et al., 2001). Men and women are now allowed to undergo voluntary sterilization as long as the individual is over 25 , is competent, has at least two children and, if married, has his or her spouse's consent. However, the law specifies that the sterilization should not be performed at the time of delivery. There should be a 65-day wait before applying for the operation. The Ministry of Health reimburses hospitals and clinics if this condition has been met and if counselling of alternative methods has been given. This law was meant to limit the number of Caesarean sections. At the same time it was meant to create awareness of different methods. However, according to Potter et al. (2001) considering the few resources that the public system has, and the strong sterilization culture that there is in Brazil, it is unlikely that this law will have an impact on medical practice in the short-term.

The other reason for such a high prevalence of female sterilization might be the increase in private family planning programmes that could be using health facilities to perform sterilization. The debate on the topic is open at the moment among Brazilian demographers and it is not clear yet whether the motivation is women asking for a Caesarean section or doctors persuading women to get sterilized (Hopkins \& Potter, 1997; Perpetuo et al., 1997). However, it is undeniable that women rely greatly on medical advice, in particular in the private sector. There is no doubt that doctors, at least in the first stages of the diffusion of sterilization, have played an important role in the increase in the number of sterilizations performed.

Nevertheless Brazilian women also use sterilization because it gives them full control over their reproductive life. The lack of inter-spousal communication that comes out the DHS data $(98 \%$ of the women do not talk about family planning with their partner) shows a strong individualism within the couple. Furthermore it shows a strong lack of confidence of the women in their partner.

It is hypothesized that sterilization decision-making is strictly linked with the level of communication in the couple. The decision to be sterilized could depend on two factors: on the one hand women who decide to get sterilized are those in stable relationships that have reached the desired family size and can see themselves continuing in the same relationship (Bailey et al., 2001). On the other hand, independent modern women who do not want to involve their partner in their reproductive life could use sterilization. In particular when the relationship is about to end and the level of communication is low, women do prefer to avoid contraceptive methods that involve negotiation like condoms or withdrawal (Bumpass \& Rindfuss, 1982; Godecker et al., 2001).

Sterilization in Brazil is highly dependent on the lack of communication between the partners. However, women in unstable unions rely on childbearing to keep their relationship, particularly in situations of economic deprivation. Furthermore it is very important for most men to show their virility through childbearing, and it is likely that they would put pressure on their partner to have another child. For these reasons they would not decrease their chances of keeping their partner by getting sterilized. At the same time women in unstable unions are less likely to have a long-term plan for their reproductive life as the precariousness of the union might lead to a general 
feeling of instability on several aspects of everyday life. In addition, the fear of regretting being sterilized can be stronger in women who feel that their relationship might not be stable (Meloni Viera \& Ford, 1996).

\section{Data and Methods}

This analysis uses 1996 DHS data. The dataset includes information for women aged 15-49. In particular the section dedicated to calendar data has been analysed. Calendar data includes information on reproductive and union histories taken retrospectively on a monthly basis for the five years preceding the survey date.

The calendar data have been re-coded in a Bernoulli format. The outcome variable is the timing of the sterilization. The women selected for the analysis are all women aged over 12 years, who have had sex at least once and who are at risk of sterilization during the calendar period. The pregnancy months have been excluded as the woman is not at risk of getting sterilized. Age has been included as a duration variable. Of the sterilization history, union history has been considered in the form of union status and union status duration. Birth interval is considered as a time varying covariate.

Event history analysis techniques and in particular discrete time models are used in this analysis. Sterilization can be considered as a non-repeatable event and the woman is censored once she has experienced the event.

The emphasis in this analysis is on the effect of union order used as a proxy for union instability, rather than any other characteristic. For this reason the analysis is limited to only a few variables without going into in-depth analysis of sterilized women.

All the duration variables (union status duration, age and birth interval duration) have been transformed into polynomial splines. Furthermore, the time varying variable parity has been included. Among the cross-sectional variables, residence in particular is relevant as it is one of the variables used for the survey design. Other variables that have been included in the model are region, religion, ethnicity, woman's occupation, women's education and whether the woman watches television at least once a week. Only the significant variables are described in the final model.

\section{Results}

The results show (Table 1) that women in second or higher order unions have a higher probability of being sterilized. However, a closer look (Table 2) reveals that this risk is higher only for nulliparous women or women with one child. The model firstly fitted without the interaction term revealed that women in second or higher order unions have a lower likelihood than women who have experienced one union only. This result should be interpreted in the light of the fact that women who have experienced more than one union have a higher family size (Table 2). Furthermore only $20 \%$ of the women in second unions have fewer than two children compared with $32 \%$ of women in their first union. It may be plausible to suggest that women in second unions are less likely to get sterilized. One of the possible explanations for this result could be related to the characteristics of women in second unions and with one or no child. It may be that such women are more independent and do not rely on 
Table 1. Discrete time model of risk of sterilization

\begin{tabular}{|c|c|c|c|c|}
\hline & Coefficients & SE & $\operatorname{Exp}(I)$ & $\begin{array}{c}N \text { (woman } \\
\text { months) }\end{array}$ \\
\hline \multicolumn{5}{|l|}{ Union status duration } \\
\hline Linear term & $0 \cdot 00734 * * *$ & $0 \cdot 002$ & $1 \cdot 007$ & \\
\hline Square term & $-0.00003^{* * *}$ & $0 \cdot 000$ & $1 \cdot 000$ & \\
\hline \multicolumn{5}{|l|}{ Union status } \\
\hline Not in union (Ref.) & & & $1 \cdot 000$ & 163,493 \\
\hline In first union & $1 \cdot 66802^{* * *}$ & $0 \cdot 173$ & $5 \cdot 302$ & 264,443 \\
\hline In second union & $1 \cdot 78605^{* * *}$ & $0 \cdot 230$ & $5 \cdot 966$ & 33,809 \\
\hline \multicolumn{5}{|l|}{ Age spline } \\
\hline Linear term & $0 \cdot 45446^{* * *}$ & 0.049 & $1 \cdot 578$ & \\
\hline Square term & $-0 \cdot 00782 * * *$ & 0.001 & 0.992 & \\
\hline \multicolumn{5}{|l|}{ Birth interval } \\
\hline Linear term & $0 \cdot 00547 * * *$ & $0 \cdot 001$ & $1 \cdot 006$ & \\
\hline Square term & $-0 \cdot 00018 * * *$ & $0 \cdot 000$ & $1 \cdot 000$ & \\
\hline Parity & $0 \cdot 51069^{* * *}$ & $0 \cdot 035$ & $1 \cdot 662$ & \\
\hline \multicolumn{5}{|l|}{ Region } \\
\hline South (Ref.) & & & $1 \cdot 000$ & 148,125 \\
\hline Centre & $0 \cdot 3790 * * *$ & $0 \cdot 087$ & $1 \cdot 528$ & 95,598 \\
\hline North-east & $0 \cdot 3520 * * *$ & $0 \cdot 111$ & $1 \cdot 422$ & 47,779 \\
\hline North & $0 \cdot 3340 * * *$ & $0 \cdot 081$ & $1 \cdot 397$ & 170,243 \\
\hline Education & $0 \cdot 02202 * * *$ & $0 \cdot 009$ & $1 \cdot 025$ & \\
\hline \multicolumn{5}{|l|}{ Watches television once a week } \\
\hline No (Ref.) & & & 1 & 60,532 \\
\hline Yes & $0 \cdot 18264^{* *}$ & $0 \cdot 090$ & $1 \cdot 200$ & 401,213 \\
\hline \multicolumn{5}{|l|}{ Residence } \\
\hline Urban & & & 1 & 370,574 \\
\hline Rural & $-0 \cdot 18894^{* * *}$ & $0 \cdot 078$ & $0 \cdot 828$ & 91,171 \\
\hline \multicolumn{5}{|l|}{ Parity by union status } \\
\hline Parity by first union & $-0 \cdot 23475^{* * *}$ & $0 \cdot 037$ & $0 \cdot 790$ & \\
\hline Parity by second or higher order union & $-0 \cdot 29392 * * *$ & $0 \cdot 046$ & $0 \cdot 745$ & \\
\hline Constant & $-14 \cdot 80912 * * *$ & 0.662 & & \\
\hline$\chi^{2}$ & $1606 \cdot 89^{* * *}$ & $\mathrm{df}=16$ & & \\
\hline
\end{tabular}

$* * * p<0 \cdot 01 ; * * 0 \cdot 01<p<0 \cdot 05 ; * 0 \cdot 05<p<0 \cdot 10$.

their partners economically. For this reason they are less likely to depend on childbearing to keep their relationship. It is also possible that these women are more in control of their reproductive life and choose a permanent method rather than a reversible one or generally a less effective one. However, women with a high level of fertility could be motivated by the idea that in each union there is need for a new child to stabilize and strengthen it.

Figures 1-3 show the trends of the relative risk of sterilization according to union duration, age and birth interval duration respectively. The trend by union duration shows that the probability of sterilization increases up to a duration of 10 years, after 
Table 2. Baseline odds ratios of sterilization by parity and union status (expressed in months)

\begin{tabular}{lccc}
\hline & Not in union & In first union & In second or higher order union \\
\hline No children & $1 \cdot 000$ & $5 \cdot 302$ & $5 \cdot 966$ \\
One child & 1.665 & $6 \cdot 983$ & $7 \cdot 404$ \\
Two children & $2 \cdot 773$ & $9 \cdot 198$ & $9 \cdot 189$ \\
Three children & 4.618 & $12 \cdot 116$ & $11 \cdot 404$ \\
\hline
\end{tabular}

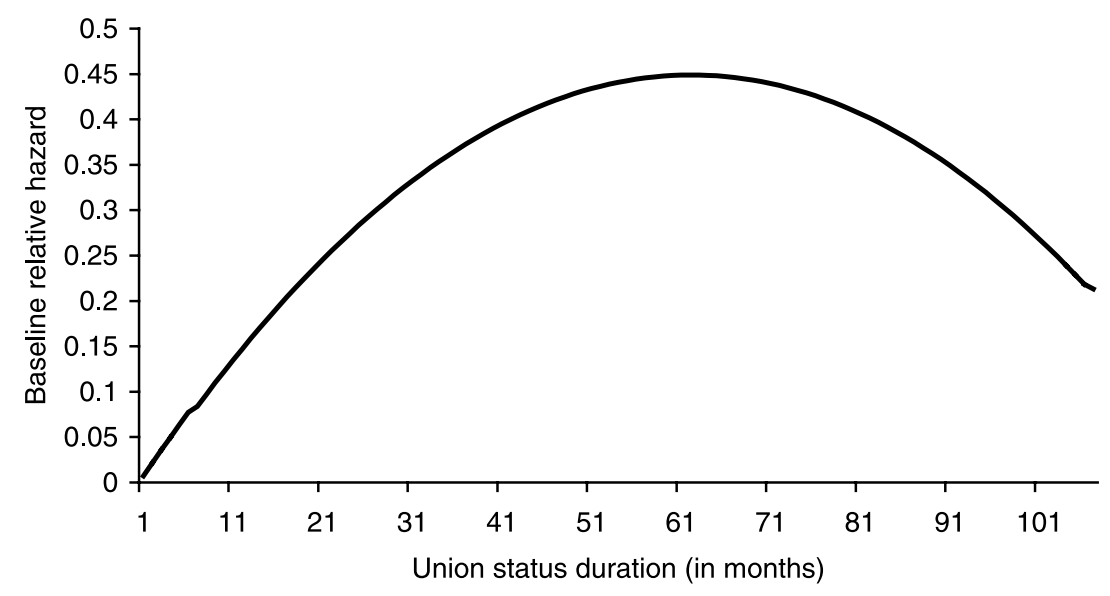

Fig. 1. Baseline relative hazard of sterilization by union status duration.

which the risk declines. The trend shows an increasing risk for young couples in particular (Fig. 1).

The relative hazard has a reversed $U$ shape by age peaking at a mean age at sterilization of 30 years (Fig. 2).

The likelihood by birth interval is high at short durations and it declines afterwards. This result could be influenced by the peculiarity of the Brazilian case as it is mentioned in the literature review (Perpetuo et al., 1997; Potter, 1999; Caetano, 2000): Brazilian women in most cases get sterilized at delivery, particularly after a Caesarean delivery.

Rural women have a lower probability of sterilization than women in urban areas. This may be directly related to exposure to the media and level of education: women living in rural areas are less educated and less exposed to the media. The level of education is positively correlated to the possibility of sterilization and at the same time women who watch television at least once a week are more likely to get sterilized. Exposure to the media appears to have a strong impact on people's reproductive life in Brazil (Rios-Neto, 2001). The mass media has a considerable effect on every stratum of the population, considerably influencing the behaviour of low-income people. This result is further supported by the regional effect: women in 


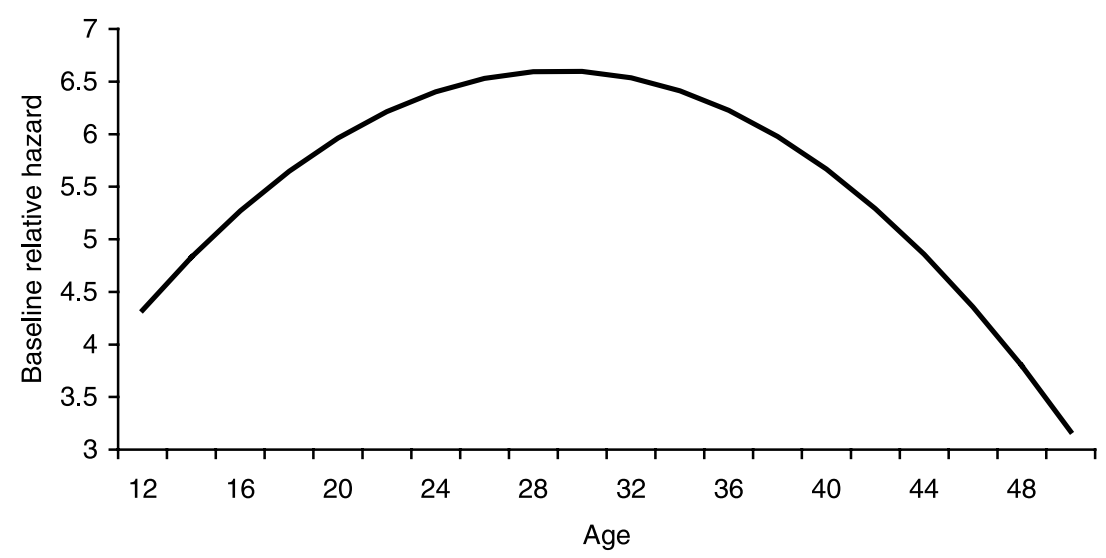

Fig. 2. Baseline relative hazard of sterilization by age.

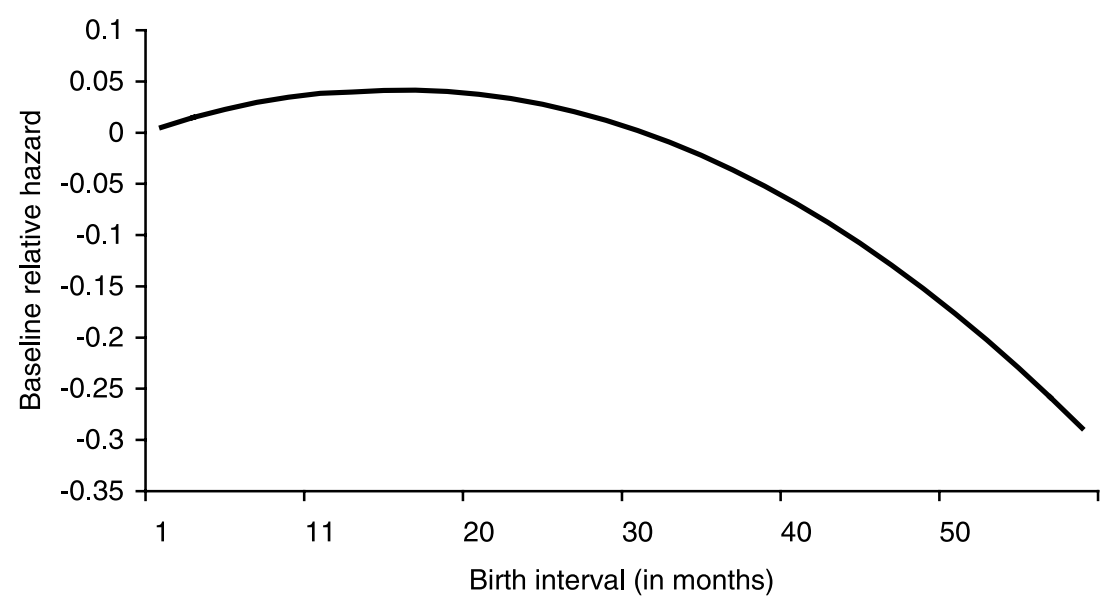

Fig. 3. Baseline relative hazard of sterilization by birth interval.

the north, usually known to be poorer, have a higher chance of being sterilized. There is evidence of an increase in poorer women requesting sterilization to avoid the high cost of childbearing. Caetano (2000) observed that women in the north-east, in particular, use political votes to pay for surgical sterilization. There is no difference, however, in the risk when considering the north and the north-east.

\section{Conclusions}

Union formation and union dissolution could affect and be affected by fertility at the same time and the study of these interactions could lead to even further studies that analyse the influence of union dynamics on contraceptive use. The lack of in-depth studies on union dynamics, in particular in the last ten years, is mainly due to the lack of data reporting complete union and fertility histories. Furthermore, it is the authors' 
belief that the importance of union dynamics has been underestimated in efforts to better understand changes in reproductive matters.

Some important factors need further investigation: women do not talk about family planning with their partners. Women like sterilization because they can be in full control of their reproductive life and stop whenever they want without relying on their partner. The analysis of the prevalence of sterilization has so far focused on the relationship between doctors and patients and on the availability of other means of contraception. There has been no attempt so far to analyse the relationship between union dynamics and contraceptive use, in particular sterilization, in Brazil. At international level as well there have been very few attempts to analyse the relationship (Bumpass \& Rindfuss, 1982; Godecker et al., 2001).

This study highlights the relationship between sterilization and union dynamics. However, further study of contraceptive choice and discontinuation could be carried out. It should aim to analyse whether women who experience more than one union make particular contraceptive choices and whether they are likely to use contraception more ineffectively or to use less-effective contraceptive methods. The DHS calendar could be a very important source of this information.

The high reliance on sterilization in Brazil creates an ethical issue for the public health community. Brazilian women do not receive information on the full range of contraceptive methods. The reluctance of the Brazilian government to promote IUDs has de facto deprived women of a fundamental right to choose their contraceptive method. This problem has been raised only in the last few years, and there is still a need for an increased awareness of the issue.

\section{References}

Bailey, W., Wynter, H., Jackson, J., Lee, A. \& Hamilton, P. (2001) Male attitude to unplanned pregnancies in Jamaica. PAA Annual Meeting, Washington DC, USA.

BEMFAM (1997) Pesquisa nacional sobre demografia e saude 1996. BEMFAM and Macro International.

Bumpass, L. \& Rindfuss, R. R. (1982) The Effect of Marital Dissolution on Contraceptive Protection. Center for Demography and Ecology, University of Wisconsin-Madison.

Caetano, A. (2000) Sterilization for votes in the Brazilian Northeast: the case of Pernambuco. $\mathrm{PhD}$ Thesis, University of Texas at Austin, Austin, USA.

Carvalho, D. M. (1997) Grandes Sistemas Nacionais de Informação em Saúde: Revisão e Discussão da Situação Atual. Informe Epidemiológico do SUS.

Carvalho, J. A. M. D. \& Wong, L. R. (1996) The fertility transition in Brazil: causes and consequences. In Guzman, J. M., Sigh, S., Rodriguez, G. \& Pantediles, E. A. (eds) The Fertility Transition in Latin America. IUSSP International Studies in Demography, Oxford University Press.

CDC \& NCHS (1998) Surgical Sterilisation in the United States: Prevalence and Characteristics, 1965-95. DHHS Publication No. (PHS)98-1996, Center for Disease Control and Prevention, National Center for Health Statistics, Hyattsville, MD.

Godecker, A. L., Thomson, E. \& Bumpass, L. L. (2001) Union status, marital history and female contraceptive sterilization in the United States. Family Planning Perspectives 33(1), 35-41.

Goldani, A. M. (2001) Rethinking Brazilian fertility decline. IUSSP XXIV General Population Conference, Salvador Bahia, Brazil. 
Greene, M. (1991) The importance of being married: marriage choice and its consequences in Brazil. Doctoral Thesis, University of Pennsylvania.

Hopkins, K. \& Potter, J. (1997) Are Brazilian women really begging for caesarean? XI Encontro Nacional de Estudos Populacionais.

Leone, T. (2002) Fertility and union dynamics in Brazil. PhD Thesis, University of Southampton, UK.

Martine, G. (1996) Brazil's fertility decline, 1965-95: a fresh look at key factors. Population and Development Review 22(1), 47-73.

Meloni Vieria, E. \& Ford, N. J. (1996) The provision of female sterilization in Sao Paulo, Brazil: a study among low income women. Social Science and Medicine 42(10), 1427-1432.

Merrick, T. W. (1983) Fertility and family planning in Brazil. International Family Planning Perspectives 9, 110-119.

Perpetuo, I. H. O. \& Aguirre, M. A. C. C. (2000) O papel da sterilizacao feminina nos diferenciais socio-economicos do declino da fecundidade in Brasil. XI Encontro Nacional Estudos Populacionais da ABEP, Brazil.

Potter, J. (1999) The persistence of outmoded contraceptive regimes. Population and Development Review 25(4), 703-739.

Potter, J., Perpetuo, I. H. O., Berquo', E., Hopkins, K., Leal, O. F., Formiga, M. C. d. C. \& Souza, M. R. (2001) Inequities and policy dilemmas in the course of an unregulated, spontaneous fertility transition: the case of Brazil. IUSSP XXIV General Poulation Conference, Salvador Bahia, Brazil.

Rios-Neto, E. (2001) Television, value constructs, and reproductive behaviour in Brazilian 'excluded communities'. IUSSP XXIV General Population Conference, Salvador Bahia, Brazil.

United Nations (1988) World Population Trends and Policies: 1987 Monitoring Report. United Nations, New York.

United Nations (1996) Levels and Trends of Contraceptive Use as Assessed in 1994. ST/ESA/ SER.A/146, New York, 1996, cited in Potter (1999). 